\title{
Ridge-furrow plastic mulching with a suitable planting density enhances rainwater productivity, grain yield and economic benefit of rainfed maize
}

\author{
ZHENG Jing $^{1}$, FAN Junliang ${ }^{1,2}$, ZOU Yufeng ${ }^{2}$, Henry Wai CHAU ${ }^{3}$, ZHANG Fucang ${ }^{1,2^{*}}$ \\ ${ }^{1}$ Key Laboratory of Agricultural Soil and Water Engineering in Arid and Semiarid Areas of Ministry of Education, Northwest \\ A\&F University, Yangling 712100, China; \\ ${ }^{2}$ Institute of Water-saving Agriculture in Arid Areas of China, Northwest A\&F University, Yangling 712100, China; \\ ${ }^{3}$ Department of Soil and Physical Sciences, Faculty of Agriculture and Life Science, Lincoln University, Canterbury 7647, \\ New Zealand
}

\begin{abstract}
Soil surface mulching and planting density regulation are widely used for effective utilization of limited rainwater resources and improvement of crop productivity in dryland farming. However, the combined effects of mulching type and planting density on maize growth and yield have been seldom studied, especially in different hydrological years. A field experiment was conducted to evaluate the effects of mulching type and planting density on the soil temperature, growth, grain yield (GY), water use efficiency (WUE) and economic benefit of rainfed maize in the drylands of northern China during 2015-2017. Precipitation fluctuated over the three years. There were four mulching types (NM, flat cultivation with non-mulching; SM, flat cultivation with straw mulching; RP, plastic-mulched ridge plus bare furrow; RPFS, plastic-mulched ridge plus straw-mulched furrow) and three planting densities (LD, low planting density, $45.0 \times 10^{3}$ plants $/ \mathrm{hm}^{2}$; MD, medium planting density, $67.5 \times 10^{3}$ plants $/ \mathrm{hm}^{2}$; HD, high planting density, $90.0 \times 10^{3}$ plants $/ \mathrm{hm}^{2}$ ). Results showed that soil temperature was higher with RP and lower with SM compared with NM, but no significant difference was found between RPFS and NM. More soil water was retained by soil mulching at the early growth stage, but it significantly varied at the middle and late growth stages. Maize growth was significantly improved by soil mulching. With increasing planting density, stem diameter, net photosynthetic rate and chlorophyll content tended to decline, whereas a single-peak trend in biomass yield was observed. Mulching type and planting density did not have significant effect on evapotranspiration (ET), but GY and WUE were significantly affected. There were significant interacting effects of mulching type and planting density on biomass yield, GY, ET and WUE. Compared with NM, RPFS, RP and SM increased GY by $57.5 \%, 50.8 \%$ and $18.9 \%$, and increased WUE by $66.6 \%, 54.3 \%$ and $18.1 \%$, respectively. At MD, GY increased by $41.4 \%$ and $25.2 \%$, and WUE increased by $38.6 \%$ and $22.4 \%$ compared with those of at LD and HD. The highest maize GY $\left(7023.2 \mathrm{~kg} / \mathrm{hm}^{2}\right)$ was observed under MD+RPFS, but the value $\left(6699.1 \mathrm{~kg} / \mathrm{hm}^{2}\right)$ was insignificant under MD+RP. Similar trends were observed for WUE under MD+RP and MD+RPFS, but no significant difference was observed between these two combinations. In terms of economic benefit, net income under MD+RP was the highest with a $9.8 \%$ increase compared with that of under MD+RPFS. Therefore, we concluded that RP cultivation pattern with a suitable planting density $\left(67.5 \times 10^{3}\right.$ plants $\left./ \mathrm{hm}^{2}\right)$ is promising for rainwater resources utilization and maize production in the drylands of northern China.
\end{abstract}

Keywords: dryland farming; evapotranspiration; net income; soil temperature; soil water storage

\footnotetext{
*Corresponding author: ZHANG Fucang (E-mail: zhangfc@nwsuaf.edu.cn)

The first and second authors contributed equally to this work.

Received 2019-03-15; revised 2019-10-30; accepted 2019-11-26

C Xinjiang Institute of Ecology and Geography, Chinese Academy of Sciences, Science Press and Springer-Verlag GmbH Germany, part of Springer Nature 2020
} 
Citation: ZHENG Jing, FAN Junliang, ZOU Yufeng, Henry Wai CHAU, ZHANG Fucang. 2020. Ridge-furrow plastic mulching with a suitable planting density enhances rainwater productivity, grain yield and economic benefit of rainfed maize. Journal of Arid Land, 12(2): 181-198. https://doi.org/10.1007/s40333-020-0001-1

\section{Introduction}

Dryland farming systems are typical in semi-arid and semi-humid drought-prone regions, where limited and erratic rainfall often leads to unstable crop yields and low water use efficiency (WUE) (Wang et al., 2007; Zhang et al., 2014; Zheng et al., 2019). Maize (Zea mays L.) is one of the main crops in the semi-arid and semi-humid drought-prone areas of northern China, representing $27.3 \%$ of the total cultivated land area (Xue et al., 2008). Due to the lack of irrigation water and facility in the gully loess regions, most farmlands rely solely on rainfall resulting in rainfed agriculture becoming the main system of farming (Chen et al., 2015). Because of large variations in rainfall amount and seasonal distribution, maize yields vary significantly in different years. The effective utilization of limited rainwater resources through appropriate agronomic practices (e.g., soil mulching and planting density regulation) is thus essential to improve rainfed maize production and WUE, and further to enhance the income of local farmers in these regions (Sharma et al., 2011; Qiang et al., 2019).

Soil mulching is an effective measure to increase rainwater productivity and crop production in dryland farming areas with an annual precipitation of 300-600 $\mathrm{mm}$ (Wang et al., 2018; Zheng et al., 2018a; Iqbal et al., 2019; Wang et al., 2019). Flat cultivation with straw mulching has been found to be effective in reducing unproductive evaporation and increasing soil water storage in dryland farming areas (Lin et al., 2016). A significant increase in crop yields and WUE due to the improved soil temperature and water storage by plastic mulching has been widely reported (Dvorak et al., 2015; Jia et al., 2018a). Ridge-furrow plastic mulching is effective for maximizing rainwater utilization. The ridges are covered by plastic film and the crops are planted in the furrows (Han et al., 2004). This cultivation pattern inhibits soil evaporation due to plastic mulching and promotes water infiltration by collecting rainwater from ridges and rainfall-coupled runoff from the furrows. This cultivation pattern can significantly increase the root-zone soil moisture availability (Zhou et al., 2009; Zhang et al., 2019). The growth season of summer maize generally starts from mid-June and ends in late September or early October. High soil temperature in the root-zone of maize plants covered with plastic film may cause leaf senescence due to a hot summer. Straw mulching in the furrow may alleviate the plastic film-induced high soil temperature by lowering soil temperature within the furrows and reduce soil water evaporation from the furrows, thus improving soil water utilization and ultimately maize productivity (Yin et al., 2017).

Planting density affects most growth indices of rainfed maize even under optimal growth conditions. It is thus considered to be a major factor affecting maize yields (Maddonni et al., 2001). To a certain extent, increasing planting density enhances the leaf area, radiation use efficiency and further improves the grain yield (GY) due to a larger plant population (Kuai et al., 2016). Maize production in dryland is heavily dependent on planting density (Berzsenyi and Tokatlidis, 2012). Maximum yield is generally achieved at an optimum planting density, depending on maize variety, climatic conditions and especially soil water availability (Sadeghi, 2013). As mentioned above, soil surface mulching can retain more soil water compared with bare soils, but soil water availability varies under different mulching types (Zhang et al., 2012). Therefore, GY of maize at a certain planting density can be variable among different mulching types, and thus the interaction effect between planting density and mulching type must be examined.

Overall, mulching type and planting density greatly affect rainfed maize growth and GY. Soil mulching can modify soil water utilization, such as reducing the ratio of evaporation to transpiration. Planting density can be easily adapted for better use of soil water and canopy light. Their independent effects on maize growth and yield have been well documented (Cook et al., 2006; Yin et al., 2017). However, the interacted effects of both mulching type and planting 
density have been relatively less studied, especially during years with different seasonal precipitation fluctuations. Few studies on the interacted effects of mulching type and planting density have been reported in other regions around the world, except for Liu et al. (2014) who evaluated the influences of plastic mulching and two planting densities on WUE and GY of rainfed maize in a semi-arid area of northwestern China. They found that plastic mulching along with increasing planting density from $65.0 \times 10^{3}$ to $85.0 \times 10^{3}$ plants $/ \mathrm{hm}^{2}$ increased maize yields and WUE. However, various mulching types resulted in changing in soil hydrothermal conditions and optimal planting density may vary consequently, especially in the semi-arid and semi-humid drought-prone regions. Thus, our objectives were to: (1) evaluate the combined effects of four mulching types and three planting densities on soil temperature and water storage, plant growth and physiological characteristics, WUE, GY and economic benefit of rainfed maize in the drylands of northern China; and (2) explore the optimal combination of mulching type and planting density on the maize hybrid "Zhengdan 958" in these regions for the high GY and net income over the three years characterized by different seasonal precipitation fluctuations.

\section{Materials and methods}

\subsection{Study area}

Field experiment was carried out at the Water-saving Station of the Key Laboratory of Agricultural Soil and Water Engineering in Arid and Semiarid Areas of Ministry of Education, Northwest A\&F University, Yangling, China $\left(34^{\circ} 18^{\prime} \mathrm{N}, 108^{\circ} 24^{\prime} \mathrm{E}\right.$; $521 \mathrm{~m}$ a.s.l.; Fig. 1) from mid-June to early October during 2015-2017. This area is characterized by a warm temperate and monsoon climate, and defined as a semi-humid drought-prone zone, where seasonal drought often occurs in spite of the relatively high annual precipitation amount (Hu et al., 2019). The mean annual precipitation from 1995 to 2014 was $561( \pm 167) \mathrm{mm}$, with $65 \%$ falling between June and September. Annual mean temperature and mean annual evapotranspiration were $13^{\circ} \mathrm{C}$ and 1500 $\mathrm{mm}$, respectively ( $\mathrm{Gu}$ et al., 2016). The soil was medium loam in texture, with a mean bulk density of $1.40 \mathrm{~g} / \mathrm{cm}^{3}$, organic matter content of $10.30 \mathrm{~g} / \mathrm{kg}$, total nitrogen content of $0.92 \mathrm{~g} / \mathrm{kg}$, $\mathrm{NH}_{4}-\mathrm{N}$ of $6.20 \mathrm{mg} / \mathrm{kg}, \mathrm{NO}_{3}-\mathrm{N}$ of $8.25 \mathrm{mg} / \mathrm{kg}$, available phosphorus of $24.90 \mathrm{mg} / \mathrm{kg}$, available potassium of $194.50 \mathrm{mg} / \mathrm{kg}$ and a $\mathrm{pH}$ of 8.14 at the $0-20 \mathrm{~cm}$ topsoil (sampled in June 2015 before sowing). The field water holding capacity and permanent wilting point of the soils were $24.0 \%$ and $8.5 \%$ (gravimetric) at the $0-20 \mathrm{~cm}$ soil depth, respectively. The groundwater table depth was greater than $50 \mathrm{~m}$.
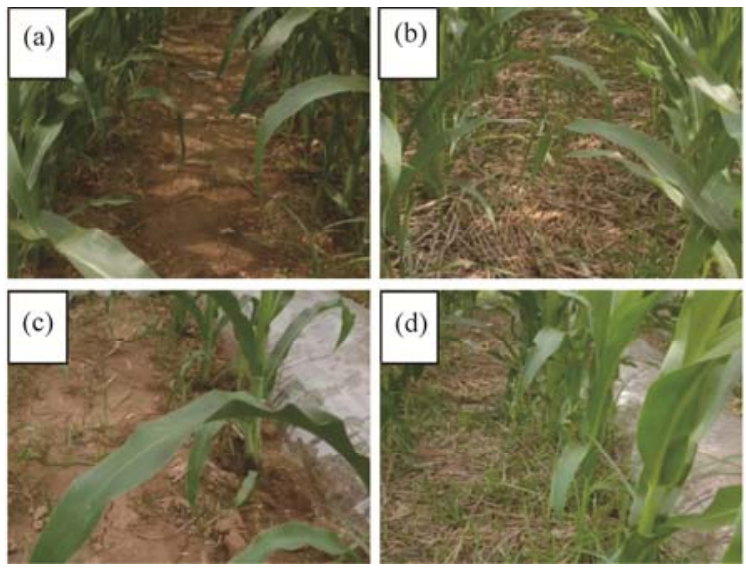

Fig. 1 Photos of different mulching types used in this study. (a), flat cultivation with non-mulching (NM); (b), flat cultivation with straw mulching (SM); (c), plastic-mulched ridge plus bare furrow (RP); (d), plastic-mulched ridge plus straw-mulched furrow (RPFS).

\subsection{Meteorological variables}

Daily values of gross rainfall $(\mathrm{mm})$, air temperature $\left({ }^{\circ} \mathrm{C}\right)$, relative humidity $(\%)$, wind speed $(\mathrm{m} / \mathrm{s})$ 
and solar radiation $\left(\mathrm{MJ} /\left(\mathrm{m}^{2} \cdot \mathrm{d}\right)\right)$ were measured using a standard automatic weather station (HOBO Event Logger, Onset Computer Corporation, USA) that was installed at $25 \mathrm{~m}$ away from the experimental plot. Vapor pressure deficit $(\mathrm{kPa})$ was calculated from air temperature and humidity (Campbell and Norman, 1998). We used the Penman-Monteith formula recommended by the Food and Agricultural Organization (FAO) to calculate daily reference crop evapotranspiration $\left(\mathrm{ET}_{0}\right)$ (Allen et al., 1998; Fan et al., 2018).

To better characterize seasonal rainfall distribution, we used anomalous percentage of precipitation $\left(P_{\mathrm{a}}\right)$ to define dryness and wetness degree (Qiang et al., 2015). The $P_{\mathrm{a}}$ is a drought index for calculating deviation of the normal precipitation, which was created to characterize and evaluate meteorological droughts at different time scales by measuring deviations between observed and average precipitation amount of a certain period. $P_{\mathrm{a}}(\%)$ was calculated as follows:

$$
\begin{gathered}
P_{a}=\frac{P-\bar{P}}{\bar{P}} \times 100 \%, \\
\bar{P}=\frac{1}{\alpha} \sum_{j=1}^{\alpha} P_{j},
\end{gathered}
$$

where $P$ is the precipitation amount for a certain period $(\mathrm{mm}) ; \bar{P}$ is the average precipitation amount during the corresponding period $(\mathrm{mm})$; and $\alpha$ is the number of years $(\alpha=20), j=1,2,3, \ldots$, $\alpha . P_{\mathrm{a}}$ values ranging from $25 \%$ to $50 \%$ are described as a partial flood, $-25 \%$ to $25 \%$ as a normal flood, $-50 \%$ to $-25 \%$ as a partial drought, $-75 \%$ to $-50 \%$ as a severe drought, and the values less than $-75 \%$ as a heavy drought.

\subsection{Experimental design}

The maize hybrid used in this study was named "Zhengdan 958", a high-yielding middle-ripening variety that was a popular maize cultivar in northwestern China. There were four mulching types (NM, flat cultivation with non-mulching; SM, flat cultivation with straw mulching; RP, plastic-mulched ridge plus bare furrow; RPFS, plastic-mulched ridge plus straw-mulched furrow) and three planting densities (LD, low planting density, $45.0 \times 10^{3}$ plants $/ \mathrm{hm}^{2}$; MD, medium planting density, $67.5 \times 10^{3}$ plants $/ \mathrm{hm}^{2}$; HD, high planting density, $90.0 \times 10^{3}$ plants $/ \mathrm{hm}^{2}$ ). The twelve treatments were replicated three times in a randomized complete factorial block design, resulting in a total of 36 experimental plots. Each plot was designed with an area of $15 \mathrm{~m}^{2}$, containing 6 rows with each row being $5 \mathrm{~m}$ long. Alternate ridges and furrows were prepared by shaping the soil surface before planting maize. The ridges $(60 \mathrm{~cm}$ wide and $15 \mathrm{~cm}$ high) were mulched with plastic film ( $80 \mathrm{~cm}$ wide and $0.008 \mathrm{~mm}$ thick), while the furrows $(60 \mathrm{~cm}$ wide) were not mulched (RP) or mulched with wheat straw (RPFS). Wheat straw was cut into $15-\mathrm{cm}$-long segments and uniformly placed over the entire soil surface with SM treatment and in the furrows with RPFS treatment at a rate of $9 \times 10^{3} \mathrm{~kg} / \mathrm{hm}^{2}$. Planting densities were employed by changing plant spacing among 37.0, 25.0 and $18.5 \mathrm{~cm}$, with a fixed row spacing of $60.0 \mathrm{~cm}$.

Maize was seeded on 15 June, 12 June and 14 June, and harvested on 30 September, 5 October and 6 October in 2015, 2016 and 2017, respectively. All treatments had emergence rates of 100\% as a result of adequate soil temperature and water content during germination, but maize seeds under the mulched treatments emerged about two days earlier than those of the non-mulched treatments. Urea $(\mathrm{N}=46 \%)$, calcium superphosphate $\left(\mathrm{P}_{2} \mathrm{O}_{5}=16 \%\right)$ and potassium sulphate $\left(\mathrm{K}_{2} \mathrm{O}=51 \%\right)$ were applied before sowing at the rates of $180 \mathrm{~kg} \mathrm{~N} / \mathrm{hm}^{2}, 120 \mathrm{~kg} \mathrm{P} / \mathrm{hm}^{2}$ and $60 \mathrm{~kg}$ $\mathrm{K} / \mathrm{hm}^{2}$, respectively.

\subsection{Sampling and measurements}

\subsubsection{Soil temperature and soil water content}

Five mercury-in-glass geothermometers (Hongxing Thermal Instruments, Wuqiang County, Hebei Province, China) were installed between two maize plants in a row at each plot at soil depths of 5, 10, 15, 20 and $25 \mathrm{~cm}$. Soil temperatures were observed at 08:00, 14:00 and 20:00 (LST, local standard time) every 10 days. The daily soil temperature was determined as the average value of three daily records.

Soil samples were collected with a core-sampling tube at depths of $0-20,20-40,40-60,60-80$, 
$80-100,100-125$ and $125-150 \mathrm{~cm}$ before sowing and after harvesting for calculating changes in soil water storage throughout the growth season. Also, soil samples to a depth of $60 \mathrm{~cm}$ at $20 \mathrm{~cm}$ intervals were collected at the middle of seedling, jointing, tasseling, filling and ripening stages to observe soil water content. The sampling positions for cultivation with ridge and furrow were located in the center of furrows, in the center of ridges and at the boundary of two adjacent ridge and furrow. For flat cultivation, soil samples were collected next to the maize plant and in between two adjacent plant rows. Soil samples were weighed wet, dried in a fan-assisted oven at $105^{\circ} \mathrm{C}$ to achieve a constant weight to determine soil water content. Soil water content was multiplied by the soil bulk density to obtain soil water content. Soil water storage was determined by multiplying soil water content by soil depth.

\subsubsection{Maize growth}

Plant height and stem diameter were measured on 10 maize plants at each growth stage of maize. Leaf area was calculated by multiplying leaf length by the largest width and then applying a correction factor of 0.75 (Mckee, 1964). Leaf area index (LAI) for each plot was then calculated by multiplying the sum of total leaf area per plant by planting density. Above-ground biomass was obtained by oven-drying the maize plants at $105^{\circ} \mathrm{C}$ for $30 \mathrm{~min}$ and at $70^{\circ} \mathrm{C}$ for $48 \mathrm{~h}$. GY was determined after harvesting at a $12.5 \%$ moisture basis for the total plot area used and harvest index (HI) was determined as maize yield divided by above-ground biomass.

\subsubsection{Net photosynthetic rate $\left(P_{\mathrm{n}}\right)$ and chlorophyll content}

$P_{\mathrm{n}}$ was measured by a LI-6400 photosynthesis system (LI-COR, Lincoln, NE, USA). The ear leaves at tasseling stage from three healthy and uniform plants at each plot were analyzed. The measurements were taken on clear days using an open system between 09:00 and 11:00. Three flag leaves from each plot were selected for $P_{\mathrm{n}}$ measurement. About $0.1 \mathrm{~g}$ fresh leaves was weighted to extract chlorophyll with $95 \%$ ethanol. The chlorophyll $a$ and $b$ contents of the filtered solution were measured at 665 and $649 \mathrm{~nm}$ by a Genesys 10 UV spectrophotometer (Thermo Electron Corporation, Madison, WI, USA), respectively. Total chlorophyll content $(\mathrm{mg} / \mathrm{g})=(13.95 \times \mathrm{A} 665-6.88 \times \mathrm{A} 649)+(24.96 \times \mathrm{A} 649-7.32 \times \mathrm{A} 665)$, where A665 and A649 are the absorbance values of the supernatant at 665 and $649 \mathrm{~nm}$, respectively (Mackinnery, 1941; Li et al., 2018).

\subsubsection{Evapotranspiration (ET) and WUE}

Seasonal ET was obtained by using soil water balance equation as follows (Fan et al., 2015; Jia et al., 2018a):

$$
\mathrm{ET}=P^{\prime}+I+C_{\mathrm{r}}+\Delta S-R-D,
$$

where ET is the evapotranspiration $(\mathrm{mm}) ; P^{\prime}$ is the net rainfall that is the amount of rainwater arriving at soil surface without interception loss by maize canopy over the growth season (mm) and is obtained from the sum of throughfall and stemflow (Zheng et al., 2018b); $I$ is the amount of irrigation (mm), with $I=0$ for the rainfed maize in our experiment; $C_{\mathrm{r}}$ is the capillary rise into the root zone $(\mathrm{mm}) ; \Delta S$ is the change in soil water storage between planting and harvesting $(\mathrm{mm}) ; R$ is the surface runoff $(\mathrm{mm})$; and $D$ is the downward drainage below crop rooting zone $(\mathrm{mm}) . C_{\mathrm{r}}$ is considered to be zero in this study because the groundwater lever is $>50 \mathrm{~m}$ deep below the surface. No surface runoff is considered due to the flat soil surface and deep percolation is also neglected as a result of low rainfall and large soil water-holding capacity in the upper $1.5 \mathrm{~m}$ soil layer. The ET was thus simplified into:

$$
\mathrm{ET}=P^{\prime}+\Delta S \text {. }
$$

WUE was further calculated as GY divided by ET, i.e., WUE=GY/ET.

\subsection{Statistical analyses}

Analyses of variances for soil temperature, soil water storage, plant height, stem diameter, leaf area index, above-ground biomass, GY, HI, ET and WUE were performed to determine the effects of mulching type, planting density and their interaction using statistical software SPSS (version 16.0, SPSS Inc., USA). Comparisons among different treatments were on the basis of least significant difference (LSD) test with a significance level of $P<0.05$. 


\section{Results}

\subsection{Meteorological conditions}

Daily mean temperatures were generally similar over three growth seasons $\left(24.1^{\circ} \mathrm{C}\right.$ in 2015 , $25.6^{\circ} \mathrm{C}$ in 2016 and $24.9^{\circ} \mathrm{C}$ in 2017), except for the higher temperatures in August 2016 compared with those in August 2015 and 2017 (Fig. 2). Values of $\mathrm{ET}_{0}$ were 413.0, 483.1 and $472.3 \mathrm{~mm}$ in 2015, 2016 and 2017, respectively. Total amount of rainfall during the growth seasons were 269.9, 261.1 and $287.4 \mathrm{~mm}$ in 2015, 2016 and 2017, respectively. There were no significant differences in terms of seasonal rainfall amount over the three years. However, seasonal rainfall amount significantly differed and it was more uniformly distributed in 2015 than in 2016 and 2017. We divided the growth season of maize into three periods according to its developmental characteristic and phenology, i.e., vegetative growth period (20 June-31 July), tasseling period (1 August-31 August), and ripening period (1 September-30 September). The rainfall amount during the growth season in 2015 was normal. However, partial flooding at vegetative growth period and severe drought at tasseling period occurred in 2016. In 2017, maize suffered from drought at an earlier period, but abundant rain occurred at ripening period (Table 1).

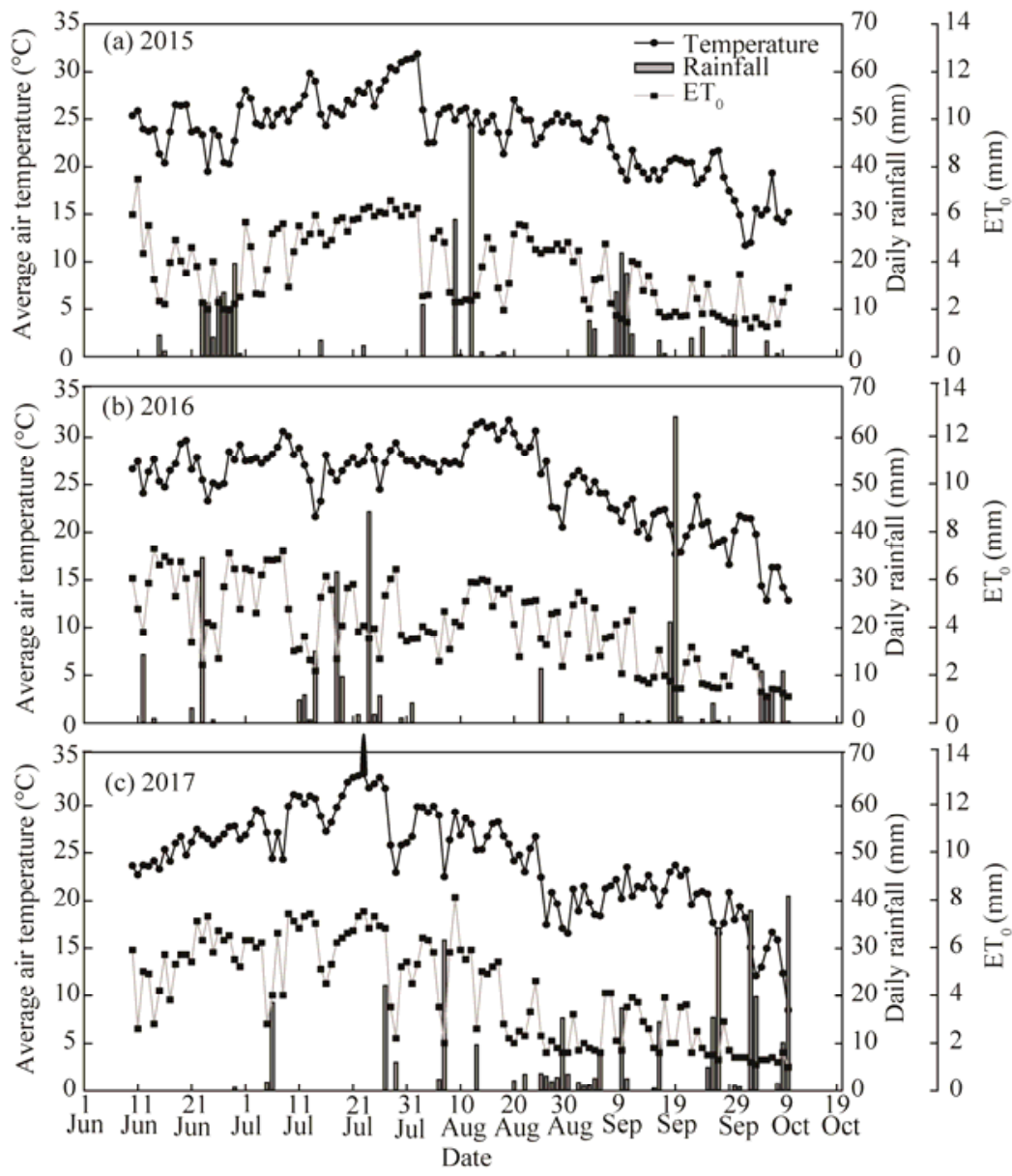

Fig. 2 Average air temperature, daily rainfall and reference evapotranspiration $\left(\mathrm{ET}_{0}\right)$ during the growth seasons in 2015 (a), 2016 (b) and 2017 (c)

\subsection{Soil temperature and soil water storage}

Effects of mulching on soil temperature were larger at the early growth stages and declined over time (Fig. 3). RP enhanced soil temperatures by $0.7^{\circ} \mathrm{C}-2.8^{\circ} \mathrm{C}$ at the $5 \mathrm{~cm}$ and by $0.5^{\circ} \mathrm{C}-2.5^{\circ} \mathrm{C}$ at the $15 \mathrm{~cm}$ soil depth compared with NM during the growth seasons. Besides, RP had a much 
Table 1 Rainfall, rainfall anomaly and drought/flood classification during the growth seasons in 2015,2016 and 2017

\begin{tabular}{|c|c|c|c|c|c|c|c|c|c|}
\hline \multirow[b]{2}{*}{ Year } & \multicolumn{3}{|c|}{$\begin{array}{c}\text { 20 June-31 July } \\
\text { (Vegetative growth period) }\end{array}$} & \multicolumn{3}{|c|}{$\begin{array}{l}1 \text { August-31 August } \\
\text { (Tasseling period) }\end{array}$} & \multicolumn{3}{|c|}{$\begin{array}{c}\text { 1 September-30 September } \\
\text { (Ripening period) }\end{array}$} \\
\hline & $\begin{array}{l}\text { Rainfall } \\
\text { (mm) }\end{array}$ & $\begin{array}{c}\text { Rainfall } \\
\text { anomaly } \\
(\%)\end{array}$ & $\begin{array}{l}\text { Drought/flood } \\
\text { classification }\end{array}$ & $\begin{array}{l}\text { Rainfall } \\
(\mathrm{mm})\end{array}$ & $\begin{array}{c}\text { Rainfall } \\
\text { anomaly } \\
(\%)\end{array}$ & $\begin{array}{l}\text { Drought/flood } \\
\text { classification }\end{array}$ & $\begin{array}{l}\text { Rainfall } \\
\text { (mm) }\end{array}$ & $\begin{array}{c}\text { Rainfall } \\
\text { anomaly } \\
(\%)\end{array}$ & $\begin{array}{l}\text { Drought/flood } \\
\text { classification }\end{array}$ \\
\hline 2015 & 87.1 & -15.9 & Normal & 88.5 & -23.2 & Normal & 94.3 & -17.3 & Normal \\
\hline 2016 & 151.7 & 46.4 & Partial flood & 15.6 & -86.5 & $\begin{array}{l}\text { Severe } \\
\text { drought }\end{array}$ & 93.8 & -17.8 & Normal \\
\hline 2017 & 48.5 & -53.2 & $\begin{array}{l}\text { Severe } \\
\text { drought }\end{array}$ & 79.6 & -30.9 & $\begin{array}{l}\text { Partial } \\
\text { drought }\end{array}$ & 159.3 & 39.6 & Partial flood \\
\hline 1995-2014 & 103.7 & - & - & 115.2 & - & - & 114.1 & - & - \\
\hline
\end{tabular}

Note: - means no value.
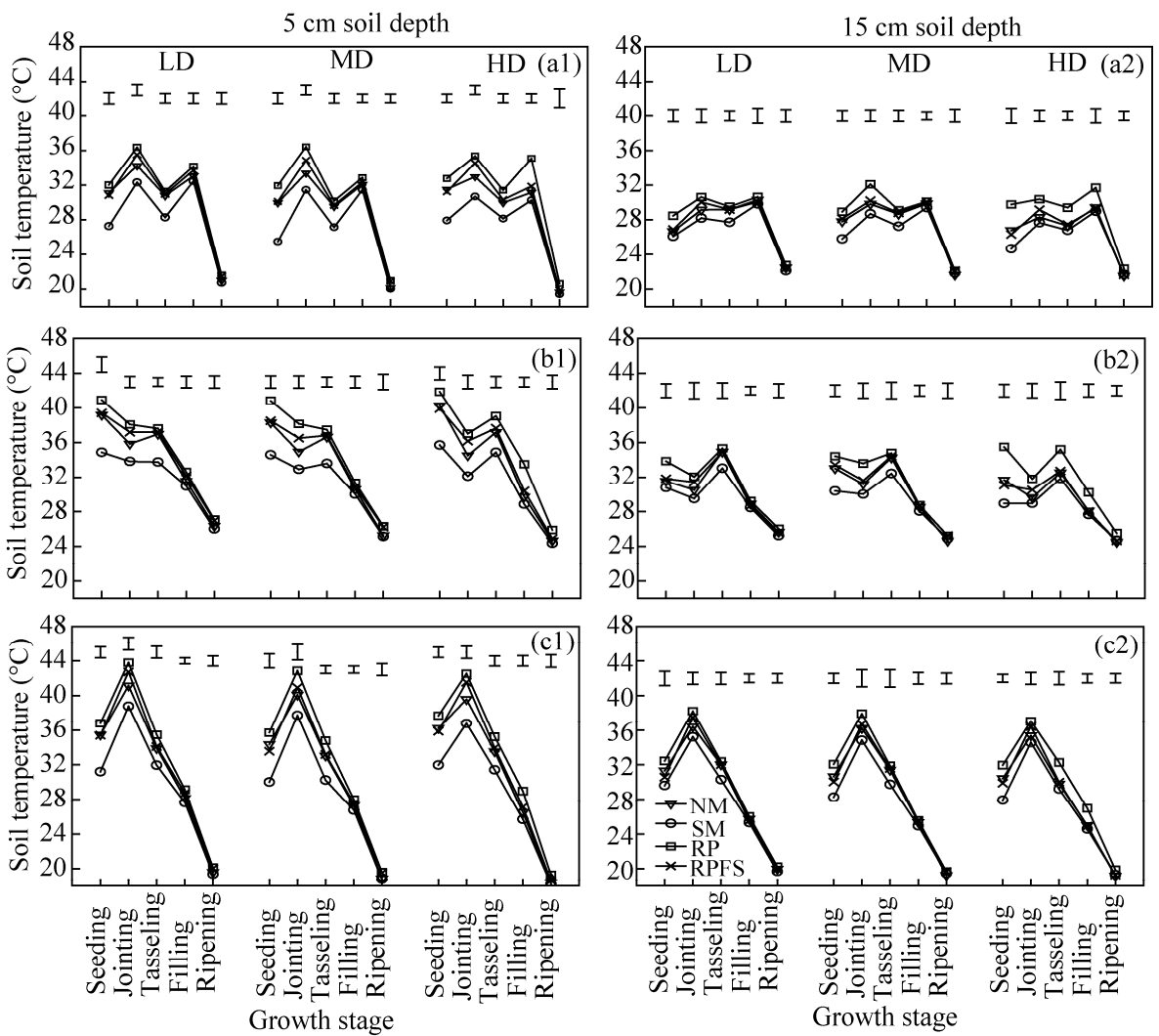

Fig. 3 Effects of mulching type and planting density on soil temperatures at the 5 and $15 \mathrm{~cm}$ soil depths at different growth stages of rainfed maize in 2015 (a1 and a2), 2016 (b1 and b2) and 2017 (c1 and c2). NM, flat cultivation with non-mulching; SM, flat cultivation with straw mulching; RP, plastic-mulched ridge plus bare furrow; RPFS, plastic-mulched ridge plus straw-mulched furrow; LD, low planting density $\left(45.0 \times 10^{3} \mathrm{plants} / \mathrm{hm}^{2}\right)$; MD, medium planting density $\left(67.5 \times 10^{3}\right.$ plants $\left./ \mathrm{hm}^{2}\right)$; HD, high planting density $\left(90.0 \times 10^{3}\right.$ plants $\left./ \mathrm{hm}^{2}\right)$. Vertical bars represent LSD values $(P<0.05)$. Abbreviations are the same in Figures 4-7 and Tables 2 and 4.

higher soil temperature than SM from seedling to filling stage at the $5 \mathrm{~cm}\left(2.0^{\circ} \mathrm{C}-6.2^{\circ} \mathrm{C}\right)$ and up to tasseling stage at the $15 \mathrm{~cm}\left(2.1^{\circ} \mathrm{C}-4.5^{\circ} \mathrm{C}\right)$ soil depth. Compared with $\mathrm{NM}$, soil average temperatures decreased by $0.0^{\circ} \mathrm{C}-4.3^{\circ} \mathrm{C}$ with straw mulching at each soil depth over the three years. There was no significant difference in soil temperatures between RPFS and NM. With increasing planting density, soil temperature had a downward trend, however, no significant difference was observed among different planting densities.

Soil water storage at the $0-60 \mathrm{~cm}$ soil depth was shown in Figure 4. In 2015, compared with $\mathrm{NM}$, average soil water storages with RPFS, RP and SM increased by $15.3,14.7$ and $4.7 \mathrm{~mm}$ at seedling stage and by $14.4,10.4$ and $4.4 \mathrm{~mm}$ at jointing stage, respectively. At tasseling and grain 
filling stages, RPFS and RP generally had lower soil water storages than SM and NM. In 2016, soil water storage with mulching treatments was higher than that of NM from seedling to harvest stage (from $0.7 \%$ to $15.3 \%$ higher on average). The values between RPFS and RP and between SM and NM were not significantly different throughout the growth seasons. In 2017, soil water storage had been decreasing from sowing to tasseling stage. Soil water storage with RPFS was the highest at seedling and jointing stages, followed by RP, SM and NM. Soil water storage generally decreased as planting density increased. Average soil water storages over three growth seasons were $2.8 \%$ and $8.0 \%$ higher at LD than at MD and HD, respectively.
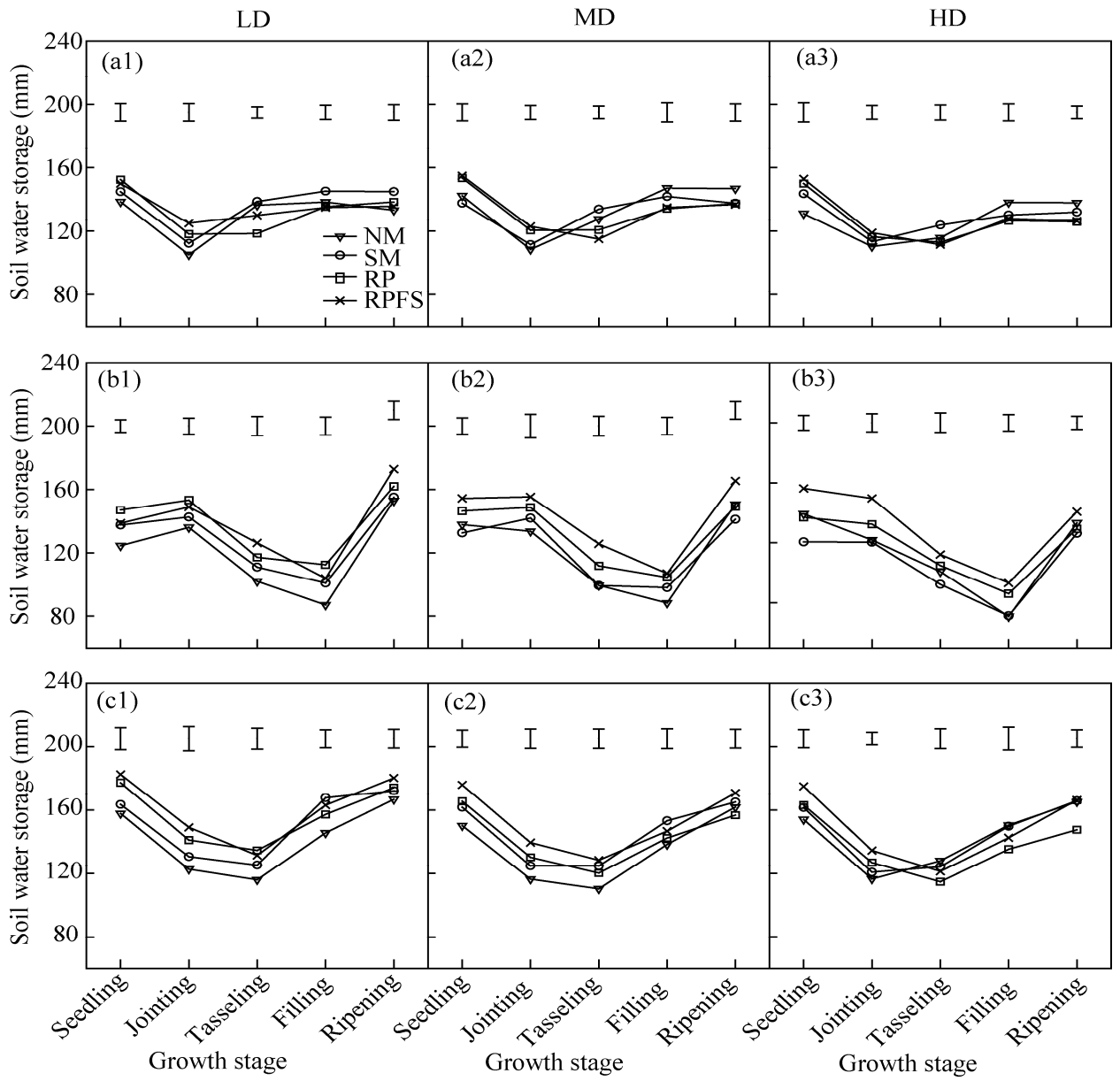

Fig. 4 Effects of mulching type and planting density on soil water storage $(0-60 \mathrm{~cm})$ at different growth stages of rainfed maize in 2015 (a1, a2 and a3), 2016 (b1, b2 and b3) and 2017 (c1, c2 and c3). Vertical bars represent LSD values $(P<0.05)$.

\subsection{Maize growth and biomass accumulation}

Maximum plant height ranged from 206.0 to $229.7 \mathrm{~cm}$ in 2015, 219.7 to $283.5 \mathrm{~cm}$ in 2016 and 199.5 to $226.0 \mathrm{~cm}$ in 2017. Maximum stem diameter ranged from 1.95 to $2.62 \mathrm{~cm}$ in $2015,2.25$ to $3.04 \mathrm{~cm}$ in 2016 and 2.17 to $2.92 \mathrm{~cm}$ in 2017 . Compared with NM, SM increased plant height and stem diameter by $2.5 \%$ and $7.7 \%$, while RP and RPFS increased plant height by $6.1 \%$ and by $8.0 \%$, and increased stem diameter by $11.2 \%$ and by $14.5 \%$, respectively. Compared with LD, MD increased plant height by $5.2 \%$ and reduced stem diameter by $3.4 \%$, while HD increased plant height by $9.5 \%$ and decreased stem diameter by $11.6 \%$ (Table 2 ). Year (Y), mulching type (M) and planting density (D) significantly affected plant height and stem diameter, however, the interaction of $\mathrm{Y} \times \mathrm{M} \times \mathrm{D}$ was not significant (Table 2 ). 


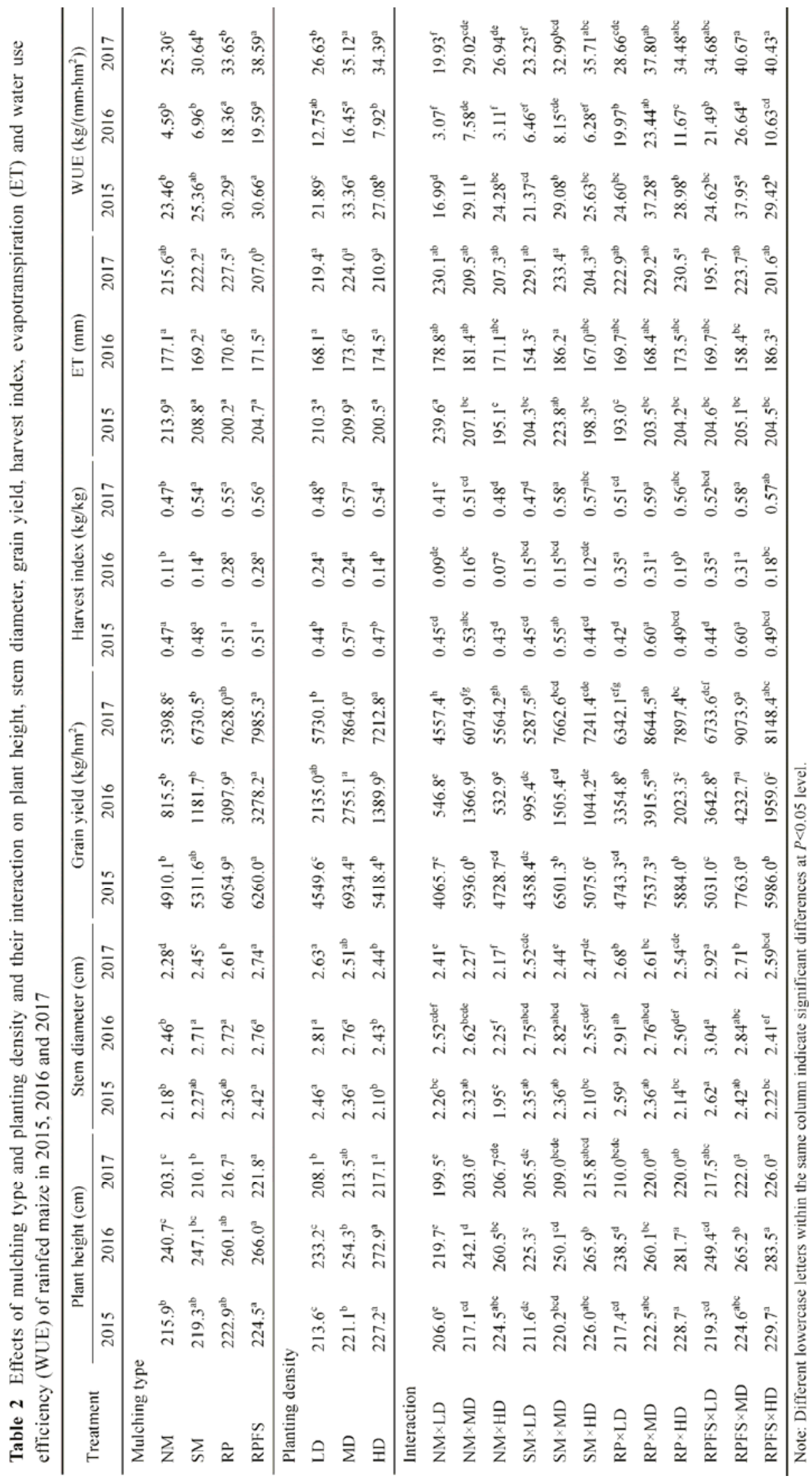


LAI generally increased from the beginning and decreased after tasseling stage because of leaf losses (Fig. 5). LAIs under different mulching types were not significantly different at the early growth stage, but LAIs with RP and RPFS were higher than those of with SM and NM at the middle and late growth stages. Soil mulching significantly increased the maximum LAI (LAI $\max _{\max }$ compared with NM. RPFS and RP increased $\mathrm{LAI}_{\max }$ by $23.6 \%$ and $13.4 \%$, while SM increased $\mathrm{LAI}_{\max }$ by $4.1 \%$ compared with NM. LAI increased with the increase in planting density. Compared with $\mathrm{LD}, \mathrm{MD}$ and $\mathrm{HD}$ increased $\mathrm{LAI}_{\max }$ by $48.2 \%$ and $82.5 \%$, respectively. Planting density had more significant effects on LAI than mulching type (Table 3). The above-ground biomass with RP and RPFS accumulated faster than those of with SM and NM after jointing stage during 2015-2017 (Fig. 6). RPFS and RP increased biomass yield by $29.2 \%$ and $24.3 \%$, while SM increased biomass yield by $8.0 \%$ compared with NM. Compared with LD, MD increased biomass yield by $22.0 \%$, while HD increased biomass yield by $13.1 \%$. Under each mulching type, MD produced the highest biomass yield over three growth seasons, but it was not significantly different from that of HD.
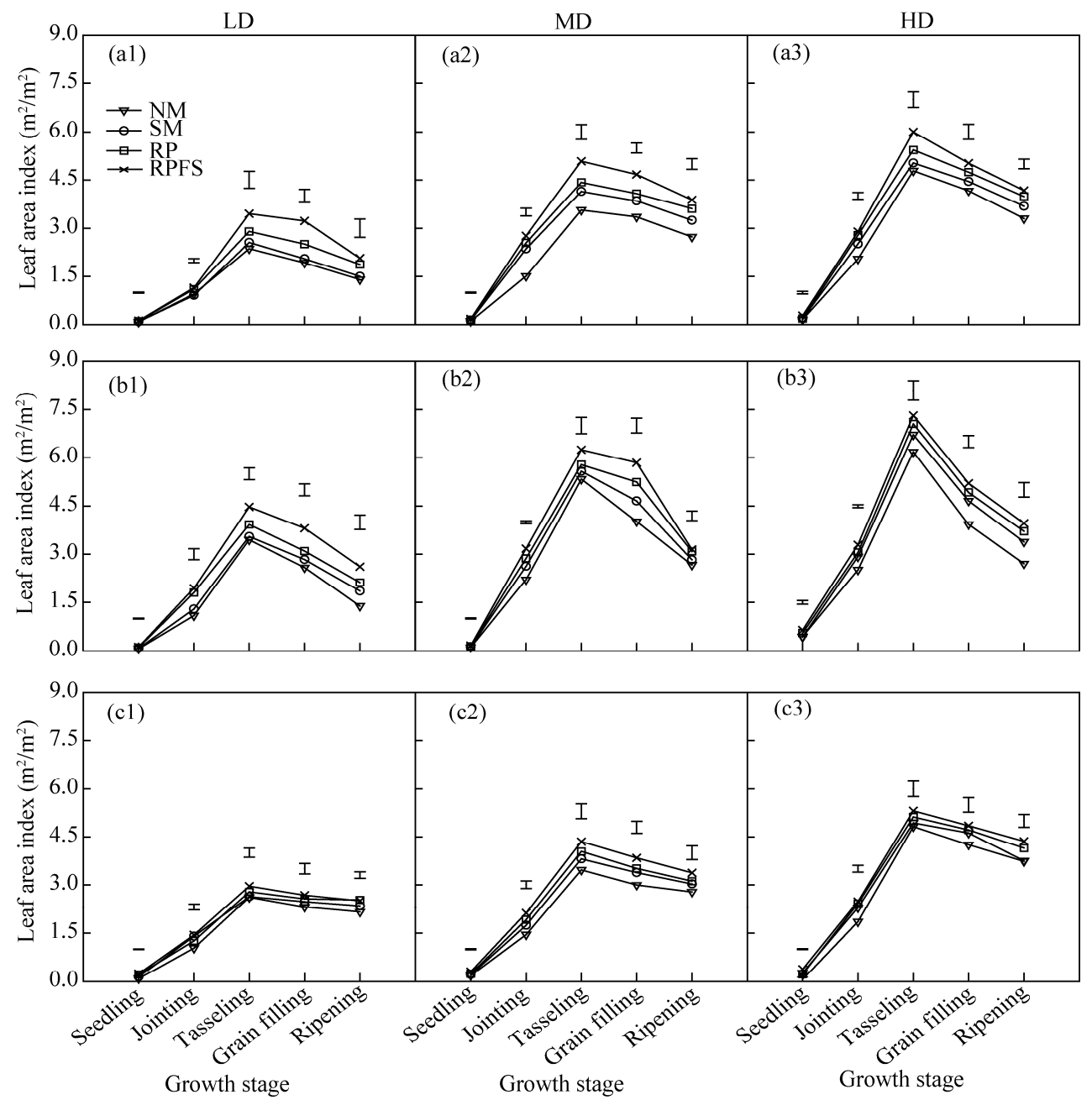

Fig. 5 Effects of mulching type and planting density on leaf area index at different growth stages of rainfed maize in 2015 (a1, a2 and a3), 2016 (b1, b2 and b3) and 2017 (c1, c2 and c3). Vertical bars represent LSD values $(P<0.05)$.

\section{$3.4 P_{\mathrm{n}}$ and chlorophyll content}

There were significant differences in $P_{\mathrm{n}}$ and chlorophyll content between different mulching types and planting density, but not their interactions (Table 3). Compared with NM, $P_{\mathrm{n}}$ with SM, RP and 
Table 3 Significance levels ( $F$ value) of the effects of different treatments (year, mulching type and planting density) and their interactions on crop growth parameters, net photosynthetic rate $\left(P_{\mathrm{n}}\right)$, chlorophyll content, biomass yield, grain yield, harvest index, evapotranspiration (ET) and water use efficiency (WUE)

\begin{tabular}{|c|c|c|c|c|c|c|c|}
\hline Parameter & Year $(Y)$ & Mulching type (M) & Planting density (D) & $\mathrm{Y} \times \mathrm{M}$ & $\mathrm{Y} \times \mathrm{D}$ & $\mathrm{M} \times \mathrm{D}$ & $\mathrm{Y} \times \mathrm{M} \times \mathrm{D}$ \\
\hline Plant height & $59.55^{* *}$ & $482.58^{* *}$ & $514.13^{* *}$ & $3.26^{*}$ & $21.37^{* *}$ & $0.56^{\mathrm{ns}}$ & $0.59^{\mathrm{ns}}$ \\
\hline Stem diameter & $41.08^{* *}$ & $42.16^{* *}$ & $52.39^{* *}$ & $1.89^{\mathrm{ns}}$ & $2.66^{\mathrm{ns}}$ & $3.54^{*}$ & $0.39^{\mathrm{ns}}$ \\
\hline Maximum LAI & $489.22^{* *}$ & $84.42^{* *}$ & $3711.80^{* *}$ & $6.82^{* *}$ & $11.93^{* *}$ & $1.94^{\mathrm{ns}}$ & $2.09^{\mathrm{ns}}$ \\
\hline$P_{\mathrm{n}}$ & $665.66^{* *}$ & $181.57^{* *}$ & $139.54^{* *}$ & $4.63^{* *}$ & $8.85^{* *}$ & $0.97^{\mathrm{ns}}$ & $2.16^{*}$ \\
\hline Chlorophyll content & $252.91^{* *}$ & $27.49^{* *}$ & $14.15^{* *}$ & $0.41^{\mathrm{ns}}$ & $0.72^{\text {ns }}$ & $0.08^{\mathrm{ns}}$ & $0.12^{\mathrm{ns}}$ \\
\hline Biomass yield & $300.64^{* *}$ & $341.67^{* *}$ & $140.13^{* *}$ & $14.33^{* *}$ & $10.80^{* *}$ & $6.57^{* *}$ & $3.32^{* *}$ \\
\hline Grain yield & $130.72^{* *}$ & $162.62^{* *}$ & $5448.56^{* *}$ & $10.06^{* *}$ & $66.52^{* *}$ & $10.79^{* *}$ & $2.79^{*}$ \\
\hline Harvest index & $140.38^{* *}$ & $76.79^{* *}$ & $120.37^{* *}$ & $9.02^{* *}$ & $40.80^{* *}$ & $2.14^{\mathrm{ns}}$ & $2.95^{*}$ \\
\hline ET & $19.55^{* *}$ & $4.43^{\mathrm{ns}}$ & $3.05^{\mathrm{ns}}$ & $2.83^{\mathrm{ns}}$ & $1.42^{\text {ns }}$ & $10.77^{* *}$ & $3.34^{* *}$ \\
\hline WUE & $61.17^{* *}$ & $378.11^{* *}$ & $219.39^{* *}$ & $4.49^{*}$ & $39.19^{* *}$ & $26.94^{* *}$ & $2.35^{*}$ \\
\hline
\end{tabular}

Note: ${ }^{*}$ and ${ }^{* *}$ mean significant differences at $P<0.05$ and $P<0.01$ levels, respectively; ${ }^{\text {ns }}$ means non-significance. LAI, leaf area index.
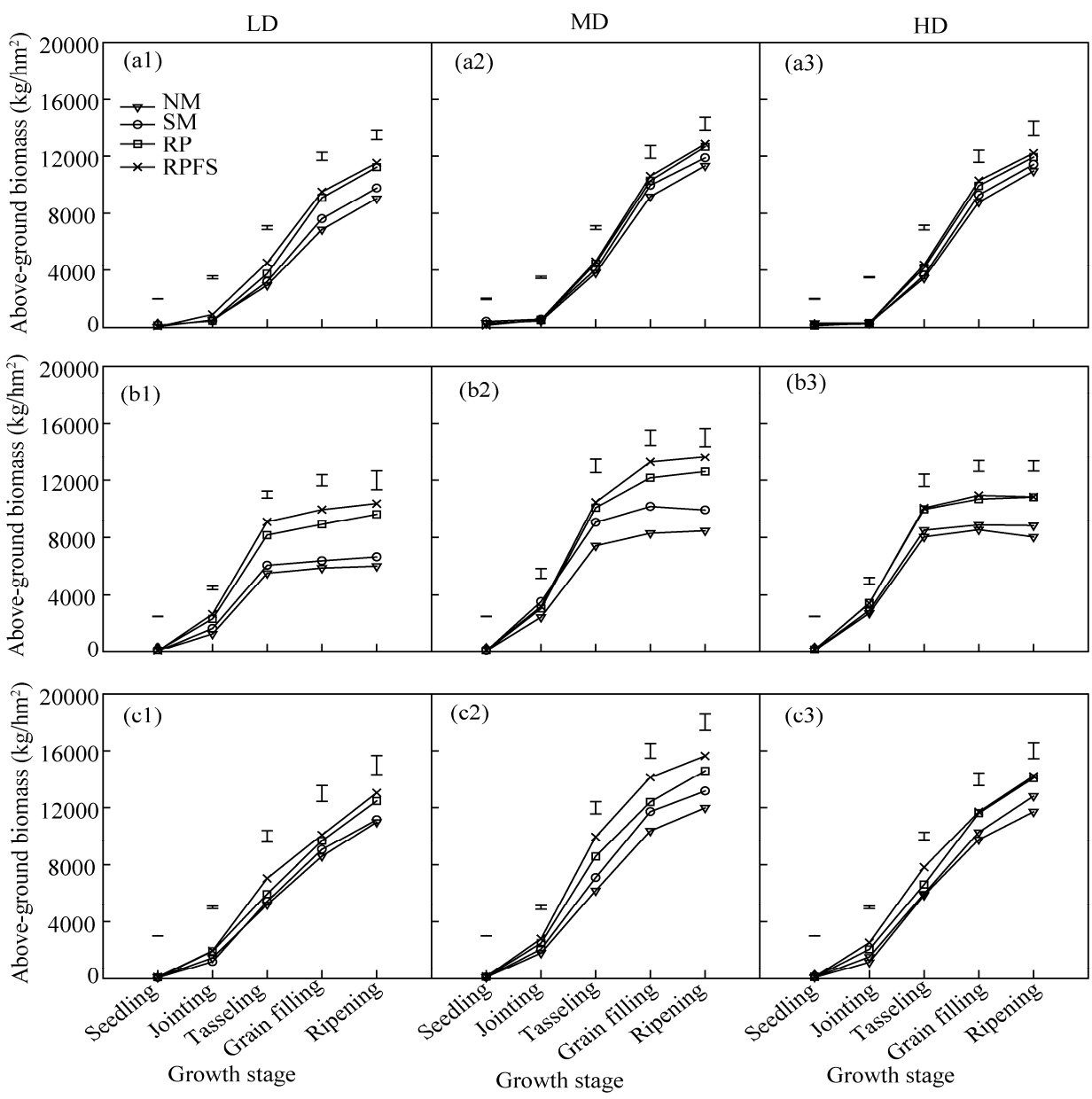

Fig. 6 Effects of mulching type and planting density on above-ground biomass at different growth stages of rainfed maize in 2015 (a1, a2 and a3), 2016 (b1, b2 and b3) and 2017 (c1, c2 and c3). Vertical bars represent LSD values $(P<0.05)$.

RPFS at tasseling stage increased by $10.3 \%, 24.0 \%$ and $34.1 \%$ in 2015, 2016 and 2017, respectively (Fig. 7). The three-year average $P_{\mathrm{n}}$ values with $\mathrm{MD}$ and $\mathrm{HD}$ at tasseling stage 
decreased by $6.6 \%$ and $17.7 \%$ compared with LD. Chlorophyll contents with RP and RPFS at tasseling stage were significantly higher $(9.3 \%$ and $13.7 \%$ higher, respectively) than that of with NM. SM increased chlorophyll content by $4.9 \%$ compared with NM, but there was no significant difference in values between NM and SM in 2015 and 2017. Chlorophyll contents with MD and HD decreased by $4.1 \%$ and $6.5 \%$, respectively compared with NM. However, no significant difference was found between LD and MD over three growth seasons. Different year treatment had very significant effects on $P_{\mathrm{n}}$ and chlorophyll content. The interactions of $\mathrm{Y} \times \mathrm{M}, \mathrm{Y} \times \mathrm{D}$ and $\mathrm{Y} \times \mathrm{M} \times \mathrm{D}$ also had significant effects on $P_{\mathrm{n}}$ but not on chlorophyll content (Table 3 ).

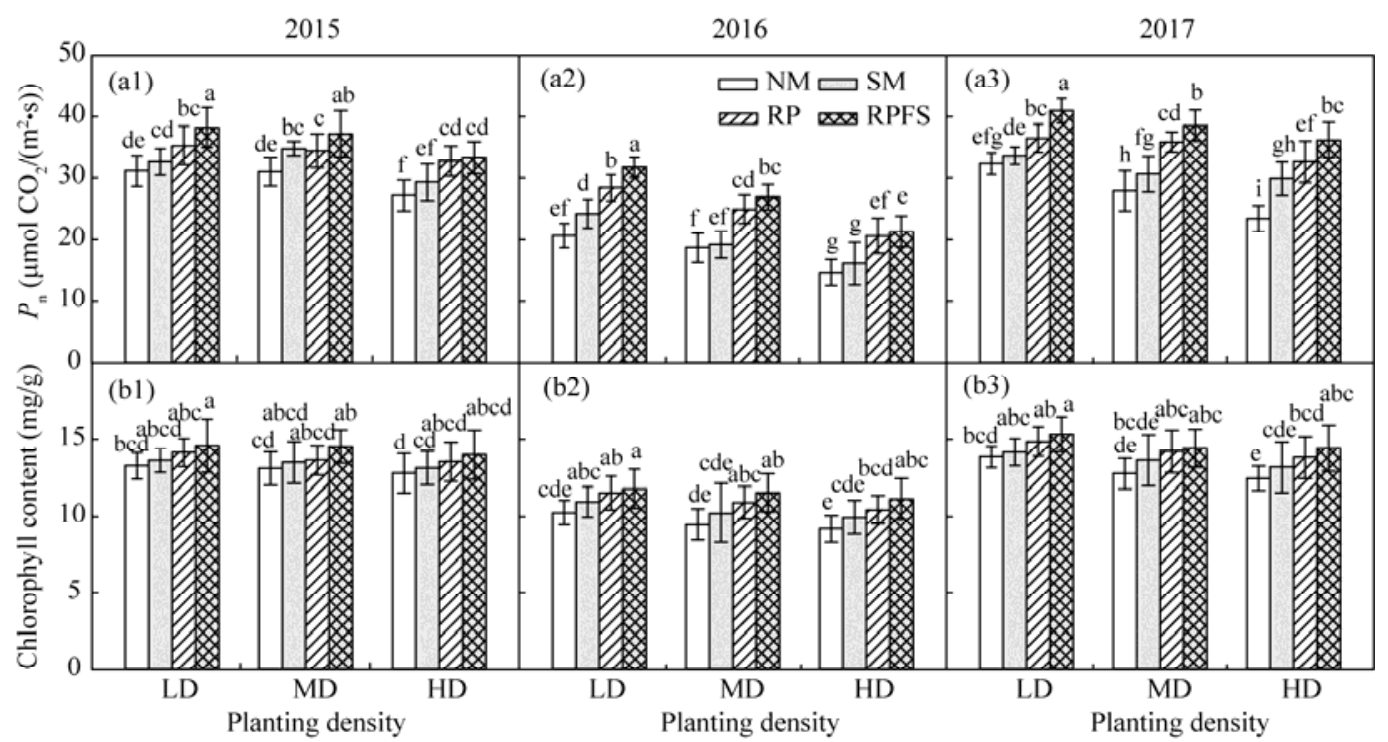

Fig. 7 Effects of mulching type and planting density on net photosynthetic rate $\left(P_{\mathrm{n}}\right.$; a1, a2 and a3) and chlorophyll content (b1, b2 and b3) at tasseling stage of rainfed maize in 2015, 2016 and 2017. Bars mean standard errors; $n=3$. Different lowercase letters indicate significant differences among different mulching types and plant densities at $P<0.05$ level.

\subsection{GY and HI}

In 2015, compared with NM, mean values of GY with SM, RP and RPFS increased by $8.2 \%$, $23.3 \%$ and $27.5 \%$, respectively. In 2016, they increased by $44.9 \%, 279.9 \%$ and $302.0 \%$, respectively. In 2017, they increased by $24.7 \%, 41.3 \%$ and $55.3 \%$, respectively (Table 2). Compared with LD, MD and HD increased GY by $52.4 \%$ and $19.1 \%$ in 2015 and by 36.0 and $24.5 \%$ in 2017 , while the corresponding values increased by $29.0 \%$ but decreased by $34.9 \%$ in 2016, respectively. Besides, effects of different planting densities on GY were more significant than those of different mulching types (Table 3). Combination of RPFS and MD produced the highest GY than other combined treatments $\left(7763.0,4232.7\right.$ and $9473.9 \mathrm{~kg} / \mathrm{hm}^{2}$ in 2015, 2016 and 2017, respectively), but GY was not significantly different between RP and RPFS over three growth seasons.

There was a tendency toward greater HI from NM to RPSF, but this tendency was not significant in 2015 (Table 2). It was significantly higher with RPFS and RP (averaged 0.28) compared with NM and SM (averaged 0.13) in 2016 and significantly higher with SM, RP and RPFS (averaged 0.56) compared with NM (0.47) in 2017. HI increased with increasing planting density from LD to MD but reduced from MD to HD. HI was similar in 2015 and 2017, ranging from 0.41 to 0.61 . It was low in 2016, ranging from 0.07 to 0.35 . Combinations of RP and RPFS at MD produced the highest HI than other combined treatments in $2015(0.60)$ and $2017(0.60)$. The highest HI in 2016 was obtained with RP and RPFS at LD (0.35), but it was not significant different from those of with RP and RPFS at MD.

\subsection{ET and WUE}

ET was not significantly affected by mulching type or planting density of maize (Table 3 ). 
Non-mulching generally produced a slightly higher ET compared with mulching, but the difference was not significant. No significant difference was found between planting densities at the same mulching type in 2015,2016 and 2017 . WUE varied from 17.0 to $38.0 \mathrm{~kg} /\left(\mathrm{mm} \cdot \mathrm{hm}^{2}\right)$ in 2015 and from 3.1 to $26.6 \mathrm{~kg} /\left(\mathrm{mm} \cdot \mathrm{hm}^{2}\right)$ in 2016 and from 19.9 to $40.7 \mathrm{~kg} /\left(\mathrm{mm} \cdot \mathrm{hm}^{2}\right)$ in 2017 . Soil mulching significantly increased WUE. RPFS and RP increased WUE by $30.7 \%$ and $29.1 \%$, while SM resulted in a lower increase in WUE by $8.1 \%$ compared with NM in 2015 . Values of WUE with SM, RP and RPFS were 51.9\%, 300.5\% and 327.1\% higher than those of with NM in 2016, respectively. In 2017, the corresponding values were $21.1 \%, 33.0 \%$ and $52.5 \%$, respectively. The highest WUE was found under RP+MD and RPFS+MD, without significant differences within the two combinations (Table 2). WUE was also significantly affected by planting density, resulting in a significantly increase initially and then a reduction as planting density increased from LD to HD with RP and RPFS.

\subsection{Economic benefit}

Total inputs mainly consisted of labour, plastic film, seed and fertilizer costs. Labour and seed costs differed due to the differences of mulching type and planting density (Table 4). Over three growth seasons, total output ranged from 1219.7 to $2328.9 \mathrm{USD} / \mathrm{hm}^{2}$ in $2015,164.0$ to 1269.8 $\mathrm{USD} / \mathrm{hm}^{2}$ in 2016 and 1367.2 to $2722.2 \mathrm{USD} / \mathrm{hm}^{2}$ in 2017 . Output value was the following order: RPFS $>\mathrm{RP}>\mathrm{SM}>\mathrm{NM}$ at the same planting density. Under the same mulching type, output value firstly increased and then decreased. However, net income with SM was slightly lower than that of with NM. This is because the application of straw increased labor input. Net income under $\mathrm{RP}+\mathrm{MD}$ was the highest and increased by 784.5, 781.1 and $1030.3 \mathrm{USD} / \mathrm{hm}^{2}$ in 2015,2016 and 2017, respectively, compared with those of under NM+LD.

Table 4 Economic benefits $\left(\mathrm{USD} / \mathrm{hm}^{2}\right)$ under different treatments

\begin{tabular}{|c|c|c|c|c|c|c|c|c|c|c|c|}
\hline \multirow{2}{*}{$\begin{array}{c}\text { Mulching } \\
\text { type }\end{array}$} & \multirow{2}{*}{$\begin{array}{c}\text { Planting } \\
\text { density }\end{array}$} & \multirow{2}{*}{$\begin{array}{c}\text { Annual } \\
\text { MMI }\end{array}$} & \multirow{2}{*}{$\begin{array}{c}\text { Annual } \\
\text { SFI }\end{array}$} & \multirow{2}{*}{$\begin{array}{c}\text { Annual } \\
\text { LI }\end{array}$} & \multirow{2}{*}{$\begin{array}{c}\text { Annual } \\
\text { TI }\end{array}$} & \multicolumn{3}{|c|}{ TO } & \multicolumn{3}{|c|}{$\mathrm{NI}$} \\
\hline & & & & & & 2015 & 2016 & 2017 & 2015 & 2016 & 2017 \\
\hline \multirow[t]{3}{*}{ NM } & LD & 0.0 & 277.8 & 518.0 & 795.8 & 1219.7 & 164.0 & 1367.2 & 423.9 & -631.8 & 571.4 \\
\hline & MD & 0.0 & 294.6 & 543.0 & 837.6 & 1780.8 & 410.1 & 1822.5 & 943.2 & -427.5 & 984.9 \\
\hline & HD & 0.0 & 311.4 & 568.0 & 879.4 & 1418.6 & 159.9 & 1669.3 & 539.2 & -719.5 & 789.9 \\
\hline \multirow[t]{3}{*}{ SM } & LD & 0.0 & 277.8 & 798.0 & 1075.8 & 1307.5 & 198.6 & 1586.3 & 231.7 & -777.2 & 510.5 \\
\hline & MD & 0.0 & 294.6 & 823.0 & 1117.6 & 1950.4 & 451.6 & 2298.8 & 832.8 & -666.0 & 1181.2 \\
\hline & HD & 0.0 & 311.4 & 848.0 & 1159.4 & 1522.5 & 313.3 & 2172.4 & 363.1 & -846.1 & 1013.0 \\
\hline \multirow[t]{3}{*}{$\mathrm{RP}$} & LD & 67.9 & 277.8 & 593.0 & 938.7 & 1423.0 & 1006.4 & 1902.6 & 484.3 & 67.7 & 963.9 \\
\hline & MD & 67.9 & 294.6 & 618.0 & 980.5 & 2261.2 & 1174.7 & 2593.4 & 1280.7 & 194.2 & 1612.9 \\
\hline & HD & 67.9 & 311.4 & 643.0 & 1022.3 & 1765.2 & 607.0 & 2369.2 & 742.9 & -415.3 & 1346.9 \\
\hline \multirow[t]{3}{*}{ RPFS } & LD & 67.9 & 277.8 & 733.0 & 1078.7 & 1509.3 & 1092.8 & 2020.1 & 430.6 & 14.1 & 941.4 \\
\hline & MD & 67.9 & 294.6 & 758.0 & 1120.5 & 2328.9 & 1269.8 & 2722.2 & 1208.4 & 149.3 & 1601.7 \\
\hline & HD & 67.9 & 311.4 & 783.0 & 1162.3 & 1795.8 & 587.7 & 2474.5 & 633.5 & -574.6 & 1312.2 \\
\hline
\end{tabular}

Note: MMI, mulching material input; SFI, seed and fertilizer input; LI, labor input; TI, total input=MMI+SFI+LI; TO, total output; NI, net income. Plastic film cost was $1.92 \mathrm{USD} / \mathrm{kg}$; labor cost was $10.00 \mathrm{USD} /($ person $\bullet$ d); maize grain price was $0.30 \mathrm{USD} / \mathrm{kg}$. Labor cost included plough, seed, weed control, harvest, drying, sheering and mulching of straw and form of ridges and furrows.

\section{Discussion}

\subsection{Effects of mulching type and planting density on maize growth and GY}

Mulching treatments improved maize growth and GY at the same planting density. At the early growth stage, temperatures in the top soil with RP were higher than that of with NM. This resulted from heating up the air and soil beneath the film by solar energy. High temperature was conducive to seedling establishment and grain formation (Zhou et al., 2009). Soil temperature with SM was lower than that of with NM. However, low temperature did not influence maize yield, but promoted maize growth in our study. This was because relatively low temperature at 
seedling stage $\left(26^{\circ} \mathrm{C}\right.$ in $2015,35^{\circ} \mathrm{C}$ in 2016 and $31^{\circ} \mathrm{C}$ in 2017$)$ was not sufficient for the emergence of summer maize. Temperature with RPFS in the top soil was not significantly different from that of with NM. This can be attributed to the trade-off effects of increased temperatures from plastic mulching on ridges and decreased temperatures from straw mulching in furrows (Li et al., 2013). In addition, better soil water retention with soil mulching at the early growth stage is critical to vegetative growth and yield of maize (Gelmond, 1978). Furthermore, photosynthetic capacity and chlorophyll content are the basis of biomass accumulation and yield formation (Ren et al., 2016), and photosynthetic characteristics are highly sensitive to the soil water stress (Ramachandra et al., 2004). Improved soil water conditions led to higher leaf chlorophyll content and net photosynthetic rate with soil mulching in this study, which resulted in a higher dry matter weight at physiological maturity and harvest stages. Liu et al. (2018) also pointed out that the ridge and furrow planting patterns could enhance individual leaf photosynthetic characteristics and obtain a higher GY.

Planting density significantly influenced maize growth and development under the same mulching type. Plant height increased with increasing planting density, which was mainly related to the competition for light (Maddonni et al., 2001). Stem diameter inversely varied with planting density, showing a decreasing trend as planting density increased. Similar result was also reported by Carpici et al. (2010), who pointed out that this trend was mostly due to the insufficient soil water supply. In this study, when planting density increased, LAI significantly increased, but above-ground biomass initially increased and then decreased. This can be attributed to the excessive vegetative growth realized from the increases in LAI at a high planting density. Medium planting density obtained a higher GY over the three years. There were several reasons for the result. First, more enhanced competition for assimilates between plants at a high planting density leads to a reduction of GY (Sadeghi, 2013). Besides, lower $P_{\mathrm{n}}$ and chlorophyll content were found at the high planting density in our study (Fig. 6), which may result from the restricted light environment within the canopy and less available mineral nutrients and water per plant (Rossini et al., 2011; Ciampitti and Vyn, 2012). This will reduce leaf photosynthetic productivity, decrease post-flowering source-sink ratio (Borras et al., 2004). In contrast, a lower planting density delays canopy closure and reduces solar radiation interception, which produces a higher GY per plant but a lower crop production per area (Abuzar et al., 2011).

The values of GY obtained in 2015 and 2017 were comparable with those of previous studies, e.g., 4805-7586 kg/hm² (Wang et al., 2011) and $8400 \mathrm{~kg} / \mathrm{hm}^{2}$ (Gao et al., 2018), respectively. However, GY obtained in $2016\left(2100 \mathrm{~kg} / \mathrm{hm}^{2}\right)$ was much lower than the above reported values. The reproductive period of maize in 2016 was characterized by much drier soil conditions due to much less rainfall and higher temperature in August compared with those in 2015 and 2017. In the study of Jia (2018b), $P_{\mathrm{n}}$ and chlorophyll content at silking and grain filling stages declined faster in the dry year (2016) than in the normal rainfall year (2015), which was in agreement with our result of inhibited leaf photosynthetic production in 2016 (Fig. 6), thus leading to the remarkable reduction in GY. Severe drought occurred at the vegetative growth stage of maize in 2017 (Table 1), resulting in a lower plant height and the maximum LAI in this year. However, the yield obtained was $23 \%$ higher in 2017 than in 2015 and $231 \%$ higher than in 2016, which was largely due to partial flooding at ripening stage. Abundant water at this critical stage could increase grain-filling rate, grain weight and enhance maize production (Jia, 2018). Yield is determined by the distribution of biomass between vegetative and reproductive organs. As a direct indicator of dry matter partitioning, $\mathrm{HI}$ is positively correlated to GY. Overall, values of HI in 2015 and 2017 were similar with those reported by Li et al. (2013) for Weibei Highlands of China. Much lower value of HI in 2016 was most likely related to the unfavorable growth conditions, i.e., low rainfall and high air temperature at tasseling and filling stages, which hampered the grain maize filling and the final yield.

In the present study, effects of mulching type and planting density and their interaction on maize growth and development were analyzed. It was found that these growth indices were significantly affected by mulching type and planting density, in which stem diameter, biomass 
yield and GY were also affected by their interaction. At the medium planting density, biomass and GY significantly increased when soil mulching was applied. However, maize yield started to decrease when planting density exceeded a certain threshold. Therefore, a reasonable planting density with suitable mulching type can achieve high yields of maize (Liu et al., 2014).

\subsection{Effects of mulching type and planting density on ET and WUE}

Our results on ET were similar to that of Lin et al. (2016), who also observed no significant differences in ET among different mulching treatments. Firstly, at the early growth stage, maize plants were small and exposed soil surface area was larger, when more soil water was lost from soil evaporation, resulting in the increase in total water loss under NM. Soil mulching decreased evaporation and subsequently ET. Secondly, maize grew more vigorously at middle and later growth stages, when plant transpiration became the dominant component of ET. This caused the higher plant transpiration under soil mulching treatments and thus a higher ET at these stages (Liu et al., 2009). Because the factors that influence transpiration and soil evaporation interact with each other, accumulative ET tended to be irregular throughout the whole growth season. ET showed various patterns under different planting densities and no significant difference was found over three growth seasons. In the study of Jia et al. (2018c), the ET before silking increased as planting density increased, but it decreased with increasing planting density after silking. Also, there were no significant differences among different plant densities in rainfed maize because limited water supply constrained the ET (Zhang et al., 2019). This was likely related to the higher soil water storage at the early growth stage and insufficient water supply for transpiration and evaporation under a high planting density at the later growth stage.

Values of WUE in our study were in good agreement with those (from 6.5 to $39.0 \mathrm{~kg} /\left(\mathrm{mm} \cdot \mathrm{hm}^{2}\right)$ ) found by Zhang et al. (2014) under different planting patterns on Chinese Loess Plateau. Various mulching types could influence soil temperature and water content, which further caused changes in WUE (Liu et al., 2016). Maximizing soil water utilization for plant transpiration is important for enhancing WUE (Blum, 2009). Soil mulching did not significantly affect ET but it changed the ways of water uptake by maize by converting more water from unproductive soil evaporation to plant transpiration, thus increasing WUE. The present study demonstrated that increasing planting density from $67.5 \times 10^{3}$ to $90.0 \times 10^{3}$ plants $/ \mathrm{hm}^{2}$ did not further enhance WUE due to the decreased GY (Table 3). Jia et al. (2018c) also found that medium planting density achieved a higher WUE compared with low and high planting densities.

WUE was also significantly affected by mulching type and planting density as well as their interaction. At LD, WUE with RPFS increased by $102 \%$ compared with that with NM. However, at $\mathrm{MD}$ and $\mathrm{HD}$, these values increased by $60.2 \%$ and $48.2 \%$, respectively. This result indicated that WUE can be maximally enhanced through a combination of RPFS and LD. Nevertheless, difference of WUE under various mulching types became smaller with increasing planting density. Under the same soil mulching type, WUE initially increased but then decreased when planting density was increased to a certain value. Thus, the highest WUE occurred under MD+RPFS, which was comparable with that under MD+RP.

\subsection{Economic benefit analysis}

Plastic mulching can increase crop yields in dryland farming areas (Ren et al., 2016). Other studies also suggested that ridge-furrow mulching had positive effects on economic benefit. However, in the study of Li et al. (2013), straw-mulched furrow had a higher net income compared with bare furrow, which was not in agreement with our results. In this study, net income with RPFS was lower than that of RP $(5.6 \%, 23.1 \%$ and $0.7 \%$ lower in 2015,2016 and 2017, respectively), because straw mulching increased labor costs. Increased GY with RPFS could not offset the increased total inputs of covering straw in furrows, leading to the relatively lower net returns. Therefore, it is concluded that RP combined with a medium planting density can serve as an optimal planting mode for maize production in this area. 


\section{Conclusions}

Optimizing mulching type and planting density can regulate soil moisture and temperature conditions, and influence maize growth and leaf photosynthetic productivity at vegetative growth stage, thereby increasing GY and WUE. Evapotranspiration did not significantly differ. However, GY and WUE were significantly affected by mulching type and planting density as well as their interaction over the three years. The highest GY of maize was observed at the medium planting density with RPFS, and similar value of GY was achieved at the medium planting density with RP. WUE had a similar trend with GY. Furthermore, MD+RP treatment brought the highest net income for farmers. Comprehensively, RP not only obtained a higher GY, but also had the largest economic benefit. Therefore, application of RP at a medium planting density $\left(67.5 \times 10^{3}\right.$ plants $/ \mathrm{hm}^{2}$ ) is recommended for the maize production in the drylands of northern China.

\section{Acknowledgements}

This study was funded by the National Natural Science Foundation of China $(51879226,51509208)$ and the Overseas Expertise Introduction Project for Discipline Innovation (111 Project; B12007).

\section{References}

Abuzar M R, Sadozai G U, Baloch M S, et al. 2011. Effect of plant population densities on yield of maize. Journal of Animal and Plant Science, 21: 692-695.

Allen R G, Pereira L S, Raes D, et al. 1998. Crop evapotranspiration-guidelines for computing crop water requirements. FAO irrigation and drainage paper 56, FAO, Rome.

Berzsenyi Z, Tokatlidis I S. 2012. Density-dependence rather than maturity determines hybrid selection in dryland maize production. Agronomy Journal, 104(2): 331-336.

Blum A. 2009. Effective use of water (EUW) and not water-use efficiency (WUE) is the target of crop yield improvement under drought stress. Field Crops Research, 112(2-3): 119-123.

Borras L, Slafer G A, Otegui M E. 2004. Seed dry weight response to source-sink manipulations in wheat, maize and soybean: a quantitative reappraisal. Field Crops Research, 86(2-3): 131-146.

Campbell G S, Norman J M. 1998. Introduction to Environmental Biophysics. New York: Springer Science+Business Media, 286.

Carpici E B, Celik N, Bayram G. 2010. Yield and quality of forage maize as influenced by plant density and nitrogen rate. Turkish Journal of Food Crop, 15(2): 128-132.

Chen Y, Liu T, Tian X, et al. 2015. Effects of plastic film combined with straw mulch on grain yield and water use efficiency of winter wheat in Loess Plateau. Field Crops Research, 172: 53-58.

Ciampitti I A, Vyn T J. 2012. Physiological perspectives of changes over time in maize yield dependency on nitrogen uptake and associated nitrogen efficiencies: a review. Field Crops Research, 133: 48-67.

Cook H F, Valdes G S B, Lee H C. 2006. Mulch effects on rainfall interception, soil physical characteristics and temperature under Zea mays L. Soil and Tillage Research, 91: 227-235.

Dvorak P, Tomâsek J, Hamouz K, et al. 2015. Reply of mulch systems on weeds and yield components in potatoes. Plant and Soil Environment, 61: 322-327.

Fan J L, Baumgartl T, Scheuermann A, et al. 2015. Modeling effects of canopy and roots on soil moisture and deep drainage. Vadose Zone Journal, 14(2): 1-18.

Fan J L, Yue W J, Wu L F, et al. 2018. Evaluation of SVM, ELM and four tree-based ensemble models for predicting daily reference evapotranspiration using limited meteorological data in different climates of China. Agricultural and Forest Meteorology, 263: 225-241.

Gao Z, Feng H Y, Liang X G, et al. 2018. Limits to maize productivity in the North China Plain: A comparison analysis for spring and summer maize. Field Crops Research, 228: 39-47.

Gelmond H. 1978. Problems in crop seed germination. In: Gupta U S. Crop Physiology. New Delhi: Oxford and IBH, 7-15.

Gu X B, Li Y N, Du Y D. 2016. Continuous ridges with film mulching improve soil water content, root growth, seed yield and water use efficiency of winter oilseed rape. Industrial Crops and Products, 85: 139-148.

Han Q F, Li X T, Wang J P, et al. 2004. Simulated study on soil moisture of field under water micro-collecting farming conditions. Transactions of the Chinese Society of Agricultural Engineering, 20: 78-82. (in Chinese) 
Hu Y J, Ma P H, Zhang B B, et al. 2019. Exploring optimal soil mulching for the wheat-maize cropping system in sub-humid drought-prone regions in China. Agricultural Water Management, 219: 59-71.

Iqbal R, Raza M A S, Saleem M F, et al. 2019. Physiological and biochemical appraisal for mulching and partial rhizosphere drying of cotton. Journal of Arid Land, 11(5): 785-794.

Jia Q M. 2018. Effects of rainwater-harvesting planting with supplemental irrigation and planting densities on the growth and photosynthetic physiology of maize in the semi-arid regions. PhD Dissertation. Yangling: Northwest A\&F University. (in Chinese)

Jia Q M, Sun L F, Shahzad A, et al. 2018a. Effect of planting density and pattern on maize yield and rainwater use efficiency in the Loess Plateau in China. Agricultural Water Management, 202: 19-32.

Jia Q M, Sun L F, Mou H Y, et al. 2018b. Effects of planting patterns and sowing densities on grain-filling, radiation use efficiency and yield of maize (Zea mays L.) in semi-arid regions. Agricultural Water Management, 201: $287-298$.

Jia Q M, Sun L F, Wang J J, et al. 2018c. Limited irrigation and planting densities for enhanced water productivity and economic returns under the ridge-furrow system in semi-arid regions of China. Field Crops Research, 221: 207-218.

Kuai J, Sun Y Y, Zhou M, et al. 2016. The effect of nitrogen application and planting density on the radiation use efficiency and the stem lignin metabolism in rapeseed (Brassica napus L.). Field Crops Research, 199: 89-98.

Li R, Hou X Q, Jia Z K, et al. 2013. Effects on soil temperature, moisture, and maize yield of cultivation with ridge and furrow mulching in the rainfed area of the Loess Plateau, China. Agricultural Water Management, 116: 101-109.

Li Y, Liu C C, Zhang J H., et al. 2018. Variation in leaf chlorophyll concentration from tropical to cold-temperate forests: Association with gross primary productivity. Ecological Indicators, 85: 383-389.

Lin W, Liu W Z, Xue Q W. 2016. Spring maize yield, soil water use and water use efficiency under plastic film and straw mulches in the Loess Plateau. Scientific Report, 6: 1-10.

Liu C A, Jin S L, Zhou L M, et al. 2009. Effects of plastic film mulch and tillage on maize productivity and soil parameters. European Journal of Agronomy, 31(4): 241-249.

Liu J L, Bu L D, Zhu L, et al. 2014. Optimizing plant density and plastic film mulch to increase maize productivity and water use efficiency in semiarid areas. Agronomy Journal, 106(4): 1138-1146.

Liu Q F, Chen Y, Liu Y, et al. 2016. Coupling effects of plastic film mulching and urea types on water use efficiency and grain yield of maize in the Loess Plateau, China. Soil and Tillage Research, 157: 1-10.

Liu T N, Chen J Z, Wang Z Y, et al. 2018. Ridge and furrow planting pattern optimizes canopy structure of summer maize and obtains higher grain yield. Field Crops Research, 219: 242-249.

Mackinnery G. 1941. Absorption of light by chlorophyll solutions. The Journal of Biological Chemistry, 140: 315-322.

Maddonni G A, Otegui M E, Cirilo A G. 2001. Plant population density, row spacing and hybrid effects on maize canopy architecture and light attenuation. Field Crops Research, 71(3): 183-193.

Mckee G W. 1964. A coefficient for computing leaf area in hybrid corn. Agronomy Journal, 56: 240-241.

Qiang S C, Zhang F C, Xiang Y Z, et al. 2015. Simulation and validation of critical nitrogen dilution curve for summer maize in Guanzhong Plain during different rainfall years. Transactions of the Chinese Society of Agricultural Engineering, 31(17): 168-175. (in Chinese)

Qiang S C, Zhang Y, Fan J L, et al. 2019. Maize yield, rainwater and nitrogen use efficiency as affected by maize genotypes and nitrogen rates on the Loess Plateau of China. Agricultural Water Management, 213: 996-1003.

Ramachandra R A, Chaitanya K V, Vivekanandan M. 2004. Drought-induced responses of photosynthesis and antioxidant metabolism in higher plants. Journal of Plant Physiology, 161(11): 1189-1202.

Ren B Z, Dong S T, Liu P, et al. 2016. Ridge tillage improves plant growth and grain yield of waterlogged summer maize. Agricultural Water Management, 177: 392-399.

Ren X L, Cai T, Chen X L, et al. 2016. Effect of rainfall concentration with different ridge widths on winter wheat production under semiarid climate. European Journal of Agronomy, 77: 20-27.

Rossini M A, Maddonni G A, Otegui M E. 2011. Inter-plant competition for resources in maize crops grown under contrasting nitrogen supply and density: Variability in plant and ear growth. Field Crops Research, 121(3): 373-380.

Sadeghi M. 2013. The determination of plant density on dry matter accumulation, grain yield and yield components of four maize hybrids. International Journal of Agriculture and Crop Sciences, 5: 109.

Sharma P, Abrol V, Sharma R K. 2011. Impact of tillage and mulch management on economics, energy requirement and crop performance in maize-wheat rotation in rainfed subhumid inceptisols, India. European Journal of Agronomy, 34(1): 46-51.

Wang X, Fan J, Xing Y, et al. 2019. The effects of mulch and nitrogen fertilizer on the soil environment of crop plants. Advance in Agronomy, 153: 121-173.

Wang X B, Cai D X, Hoogmoed W B, et al. 2007. Crop residue, manure and fertilizer in dryland maize under reduced tillage in 
northern China: I grain yields and nutrient use efficiencies. Nutrient Cycling in Agroecosystems, 79(1): 1-16.

Wang T C, Wei L, Wang H Z, et al. 2011. Responses of rainwater conservation, precipitation-use efficiency and grain yield of summer maize to a furrow-planting and straw-mulching system in northern China. Field Crops Research, 124(2): 223-230.

Wang Y Q, Zhang Y H, Zhou S L, et al. 2018. Meta-analysis of no-tillage effect on wheat and maize water use efficiency in China. Science of the Total Environment, 635: 1372-1382.

Xue J Q, Zhang R H, Li F Y, et al. 2008. Current status, problem and strategy of maize breeding in Shannxi Province. Journal of Maize Science, 16(2): 139-141. (in Chinese)

Yin W, Chen G P, Feng F X, et al. 2017. Straw retention combined with plastic mulching improves compensation of intercropped maize in arid environment. Field Crops Research, 204: 42-51.

Zhang F, Ibrahim M E, Li M, et al. 2019. Integrated model and field experiment to determine the optimum planting density in plastic film mulched rainfed agriculture. Agricultural and Forest Meteorology, 268: 331-340.

Zhang H J, Dong H Z, Li W J, et al. 2012. Effects of soil salinity and plant density on yield and leaf senescence of field-grown cotton. Journal of Agronomy and Crop Science, 198(1): 27-37.

Zhang S H, Sadras V, Chen X P, et al. 2014. Water use efficiency of dryland maize in the Loess Plateau of China in response to crop management. Field Crops Research, 163: 55-63.

Zhang X D, Zhao J, Yang L C, et al. 2019. Ridge-furrow mulching system regulates diurnal temperature amplitude and wetting-drying alternation behavior in soil to promote maize growth and water use in a semiarid region. Field Crops Research, 233: 121-130.

Zhang Y Q, Wang J D, Gong S H, et al. 2019. Straw mulching enhanced the photosynthetic capacity of field maize by increasing the leaf $\mathrm{N}$ use efficiency. Agricultural Water Management, 218: 60-67.

Zheng J, Fan J L, Zhang F C, et al. 2018a. Mulching mode and planting density affect canopy interception loss of rainfall and water use efficiency of dryland maize on the Loess Plateau of China. Journal of Arid Land, 10(5): 794-808.

Zheng J, Fan J L, Zhang F C, et al. 2018b. Rainfall partitioning into throughfall, stemflow and interception loss by maize canopy on the semi-arid Loess Plateau of China. Agricultural Water Management, 195: 25-36.

Zheng J, Fan J L, Zhang F C, et al. 2019. Throughfall and stemflow heterogeneity under the maize canopy and its effect on soil water distribution at the row scale. Science of the Total Environment, 660: 1367-1382.

Zhou L M, Li F M, Jin S L, et al. 2009. How two ridges and the furrow mulched with plastic film affect soil water, soil temperature and yield of maize on the semiarid Loess Plateau of China. Field Crops Research, 113(1): 41-47. 